\title{
Review Article \\ Thyroid-Specific Transcription Factors and Their Roles in Thyroid Cancer
}

\author{
Shioko Kimura \\ Laboratory of Metabolism, National Cancer Institute, National Institutes of Health, Bethesda, MD 20892, USA \\ Correspondence should be addressed to Shioko Kimura, kimuras@mail.nih.gov \\ Received 14 January 2011; Accepted 17 February 2011 \\ Academic Editor: Daniel Christophe \\ Copyright (C) 2011 Shioko Kimura. This is an open access article distributed under the Creative Commons Attribution License, \\ which permits unrestricted use, distribution, and reproduction in any medium, provided the original work is properly cited. \\ Homeodomain, forkhead domain, and paired domain-containing transcription factors play a major role in development, tissue- \\ specific gene expression, and tissue homeostasis in organs where they are expressed. Recently, their roles in stem cell and cancer \\ biology are emerging. In the thyroid, NKX2-1, FOXE1, and PAX8 transcription factors are responsible for thyroid organogenesis \\ and expression of thyroid-specific genes critical for thyroid hormone synthesis. In contrast to their known roles in gene regulation, \\ thyroid development and homeostasis, their involvement in stem cell, and/or cancer biology are still elusive. In order to further \\ understand the nature of thyroid cancer, it is critical to determine their roles in thyroid cancer.
}

\section{Introduction}

Tissue-specific transcription factors play a pivotal role in regulating expression of tissue-specific genes, thereby controlling the function, homeostasis, and differentiation of tissue where they are expressed. Their altered expression due to gene mutation, deletion, amplification, and/or epigenetic modification, and/or posttranslational modification can change the cell fate and perturb metabolism and differentiation status, leading to various clinical conditions. Since both cell proliferation and differentiation are involved in the process of normal and cancer development, it is not surprising that genes critical for development play an important role in oncogenesis. Transcription factors, containing the homeobox [1,2], forkhead domain (FOX) [3], and paired domain (PAX) [4], that are among those expressed tissuespecifically that play a critical role in tissue homeostasis and development, can also have roles in carcinogenesis. Thyroid is an organ in which the homeodomain, forkhead domain, and paired domain-containing transcription factors all play major roles in tissue-specific gene expression and thyroid development. The current view on the roles of thyroidspecific transcription factors in thyroid cancer will be summarized below.

\section{Thyroid-Specific Transcription Factors}

The three distinct thyroid-specific transcription factors are critical for the function of thyroid: NKX2-1 (also called TTF1, TITF1, T/EBP, or NKX2.1) [5, 6], FOXE1 (also called TTF2 or TITF2) [7], and PAX8 [8] (Table 1). They are members of the homeodomain, forkhead box, and paired box family of transcription factors, respectively, and regulate genes encoding thyroglobulin, thyroid peroxidase, thyrotropin receptor, and sodium/iodide symporter, proteins critical for thyroid hormone synthesis [5-7, 9-14]. They are also essential for thyroid development [15-17]; Nkx2-1-null mice are born without the thyroid (agenesis) [16], while Pax8-null mice are severely hypothyroidism with rudimental thyroid remnant [17]. Foxe1-null mice have either agenesis or thyroid ectopy [15]. These transcription factors are responsible for the athyreosis, hypothyroidism, and/or ectopic thyroid, which provide crucial clues to their roles in thyroid dysgenesis in humans [18]. In addition to thyroid, NKX2-1 is expressed in lung primordium and ventral forebrain [16], PAX8 in developing kidney [8], and FOXE1 in the floor of the foregut and the craniopharyngeal ectoderm including Rathke's pouch during development [15]. At later stages, FOXE1 is expressed in the secondary palate, definitive 
TABLE 1: Thyroid-specific transcription factors and thyroid cancers.

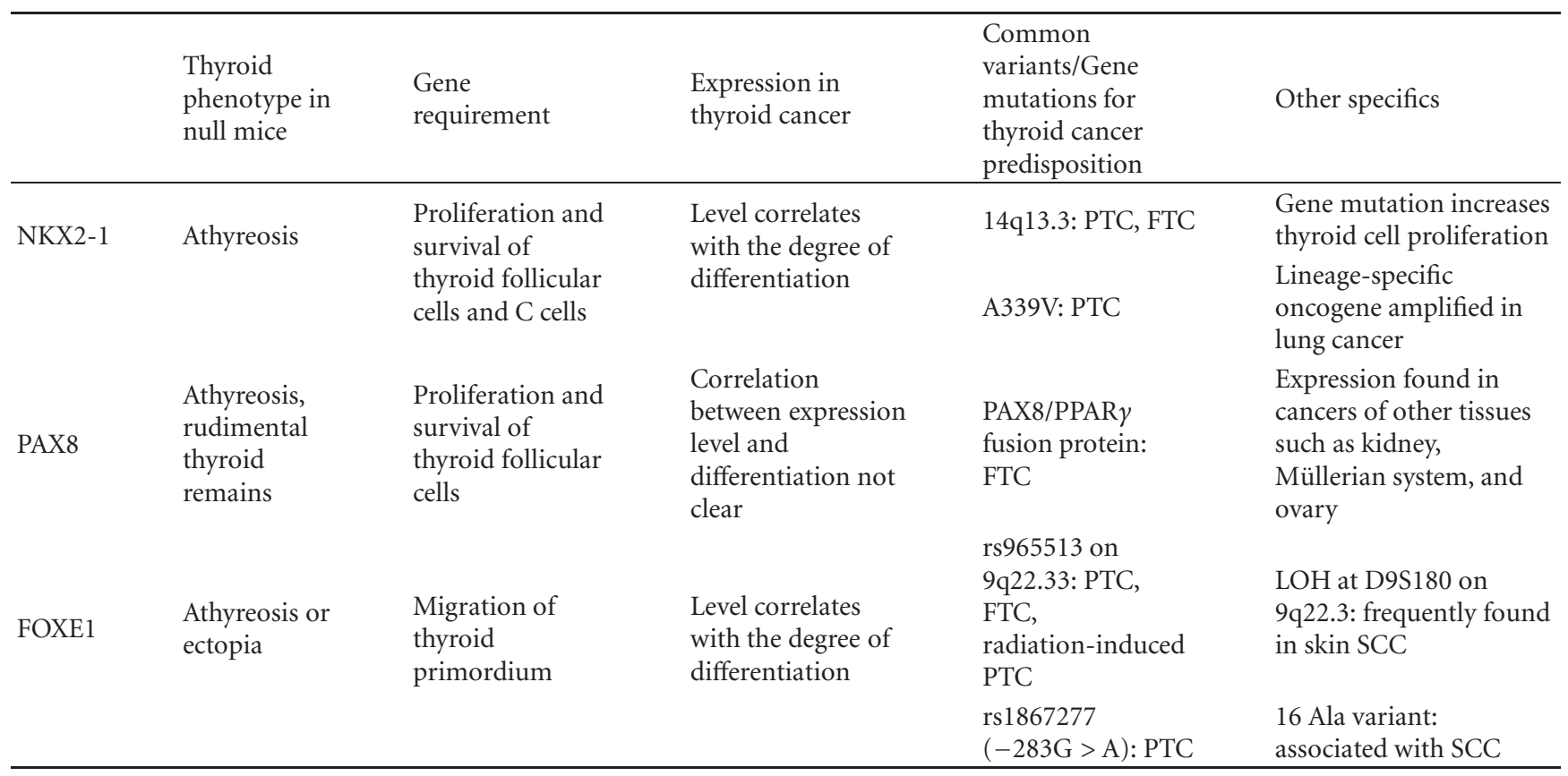

PTC: papillary thyroid carcinoma, FTC: follicular thyroid carcinoma, SCC: squamous cell carcinoma, and LOH: loss of heterozygosity.

choanae, whiskers, and hair follicles [19]. Some structures derived from these areas are also defective in respective null mice. Thus, Nkx2-1-null mice also have severely hypoplastic lung, defective hypothalamus, and pituitary agenesis [16]. Foxe1-null mice have cleft palate [15]. Similar to the defects found in the Nkx2-1-null mice and sometimes more manifested in humans, various mutations in the NKX2-1 gene result in the Brain-Thyroid-Lung syndrome, which is characterized by benign hereditary chorea, congenital hypothyroidism, and respiratory diseases [20-22]. Mutations in the FOXE1 gene are responsible for syndromic congenital hypothyroidism dysgenesis, cleft plate, and spiky hair [22-24].

\subsection{NKX2-1}

2.1.1. NKX2-1 and Cancer. Due to the nature of tissuespecific expression, NKX2-1 is expressed in human thyroid and lung cancers [25-28]. In particular, NKX2-1 is highly expressed in human lung adenocarcinomas and small cell carcinomas $(\sim 60-90 \%)[25,26,29]$. NKX2-1 has been widely used as a marker for the diagnosis of primary and metastatic lung cancer [30] and as a prognostic indicator for survival $[26,31,32]$. In fact, NKX2-1 is a lineage-specific oncogene amplified in lung cancers and the survival of a subset of adenocarcinoma cells depends on the sustained expression of NKX2-1 [33-35]. However, no mutations in the NKX2-1 gene are described in any adenocarcinomas examined in these studies. Patients with adenocarcinomas that lack NKX2-1 expression or have NKX2-1 expression accompanied by NKX2-1 gene amplification tend to have a significantly worse prognosis than patients with NKX2-1 expression and no NKX2-1 gene amplification [32].

In contrast to the expression in lung, NKX2-1 is expressed at lower levels in malignant thyroid as compared to normal thyroid [36]. The level of expression is significantly correlated with the progressive dedifferentiation and increase of malignancy of thyroid tumors [27]. Thus, the expression is generally found in the order of follicular thyroid adenoma $>$ follicular thyroid carcinoma $>$ papillary thyroid carcinoma $>$ medullary thyroid carcinoma $>$ anaplastic thyroid carcinoma [27, 37-39]. These studies use immunohistochemical analysis of primary thyroid tissues, and low or no expression of NKX2-1 is found in anaplastic thyroid carcinomas. Using RT-PCR, NKX2-1 expression is reported in some anaplastic thyroid carcinoma-derived cell lines [40, 41]. The latter studies present different results for the expression of NKX21 within the same cell line, suggesting the controversial nature of NKX2-1 expression. In order to explain the loss of NKX2-1 expression in most of undifferentiated thyroid carcinomas and cell lines, epigenetic silencing of the NKX21 gene through DNA hypermethylation and histone $\mathrm{H} 3$ modification has been suggested [40]. Further studies are required to obtain clear understanding of the relationships in between expression of NKX2-1, differentiation status of tissues and primary carcinomas versus cell lines, and the mechanisms underlying the loss of NKX2-1 expression in malignancy.

A genome-wide association study (GWAS) revealed the predisposition of common variants on $9 \mathrm{q} 22.33$ and $14 \mathrm{q} 13.3$ to both papillary and follicular thyroid cancers. The gene nearest to the 9q22.33 is FOXE1, and among the genes located at the 14q13.3 locus is NKX2-1 [42], suggesting 
potential roles for these two thyroid-specific transcription factors in thyroid cancers. A germline mutation of NKX2-1 gene leads to a mutant NKX2-1 protein $(\mathrm{A} 339 \mathrm{~V})$ that has impaired transactivation of thyroid-specific genes such as thyroglobulin, thyrotropin receptor, and PAX8, while the expression is associated with the increased cell proliferation, thyrotropin-independent growth, and enhanced activation of survival signaling molecules such as Stat3 and Akt as compared to wild-type protein [43]. A population study demonstrated that the NKX2-1 A339V mutant contributes to predisposition of maltinodular goiter and/or papillary thyroid carcinomas and to the pathogenesis of papillary thyroid carcinomas [43].

2.1.2. Nkx2-1 Thyroid-Specific Conditional Knockout Mouse as a Model to Study Thyroid Carcinogenesis. Nkx2-1(fl/fl);TPOCre thyroid-specific conditional knockout mouse provides an animal model to study the role of NKX2-1 in adult thyroid, which circumvents the problem of immediate neonatal lethality of Nkx2-1-null mouse [44]. In the Nkx21(fl/fl);TPO-Cre mouse, the recombination of Nkx2-1 floxed gene occurs at the rate of $\sim 50 \%$, resulting in Nkx2-1 thyroidspecific conditional hypomorphic mouse [45]. These mice exhibit either atrophic/degenerative thyroids with frequent presence of adenomas and extremely high TSH levels, or thyroids with reduced numbers of extremely dilated follicles having more number of follicular cells than usual within a follicle. The atrophic/degenerative thyroid mostly consists of atrophic/degenerative follicles, in which many follicular cells frequently have lost NKX2-1 expression, suggesting that the loss of NKX2-1 may be the cause of atrophic/ degenerative follicular cells [45]. These findings further suggest that NKX2-1 is required for the maintenance of ordered architecture and function of the differentiated thyroid [45].

In chemical carcinogenesis bioassays using the genotoxic mutagen N-bis(2-hydroxypropyl)-nitrosamine (DHPN) followed by sulfadimethoxine (SDM) as a promoter, the Nkx2$1(f l / f l)$;TPO-Cre mice developed significantly higher incidence of adenomas as compared with wild-type or Nkx2-1heterozygous mice [46]. In contrast, with the non-genotoxic carcinogen amitrole (3-amino-1,2,4-triazole), all three genotype groups of mice developed adenomas at similar incidence. Surprisingly, no gene mutation was identified in any adenoma-developed thyroids. The increased incidence of adenomas in the Nkx2-1(fl/fl);TPO-Cre mice after genotoxic carcinogen exposure may be partially explained by more than a twofold higher cell proliferation rate found in these mouse thyroids as compared to those of wild-type or Nkx2-1heterozygous mice. These results may be analogous to human exposure to genotoxic mutagens or radiation, which could cause somatic mutation of NKX2-1 gene $\rightarrow$ inactivation of NKX2-1 gene $\rightarrow$ degeneration of thyroid follicular cells $\rightarrow$ increased cell proliferation $\rightarrow$ augmentation of the damage occurred in DNA, and/or chromosomes by genotoxic mutagens or radiation exposure, ultimately leading to cancer [46].
2.2. FOXE1 and Cancer. The human FOEX1 gene is located on chromosome 9q22.3 [47]. The loss of heterozygosity of marker D9S180 from this chromosomal area is frequently observed in squamous cell carcinomas of skin, suggesting the presence of tumor suppressor gene in this genomic region [48]. The common variant rs 965513 on 9q22.33 contributes to an increased risk of papillary and follicular thyroid cancer [42]. Further, a high incidence of FOXE1 gene promoter methylation is found in cutaneous squamous cell carinomas (SCC) [49], pancreatic cancers [50], and breast cancers [51]. FOXE1 protein has a polyalanine tract starting at the 13th amino acid residue from the end of the forkhead domain, which stretches from 12 to 17 residues with the 14 alanine stretch at the highest frequency [47]. The less common variant (allele 16) is associated with SCC, suggesting that the more common variant (allele 14) may be protective against developing SCC [52].

Similar to NKX2-1, FOXE1 expression is found in various thyroid cancers $[38,53]$. The level of expression correlates with their differentiation status as seen with NKX2-1, and anaplastic thyroid carcinoma has very little expression of FOXE1 $[38,53]$. The candidate gene association study revealed that the variant $\mathrm{rs} 1867277(-283 \mathrm{G}>\mathrm{A})$ located in the FOXE1 5' UTR is associated with papillary thyroid cancer susceptibility through recruitment of USF1/USF2 transcription factors to the $-283 \mathrm{~A}$ allele, which affects gene expression [54]. FOXE1 is required for thyroid cell precursors to migrate into the underlying mesenchyme from the thyroid bud [15, 55]. Although the exact mechanism for the enhanced transcription of FOXE1 gene leading to increased susceptibility to papillary thyroid cancer remains unknown, the enhanced expression of FOXE1 in thyroid carcinomas could be related to a motile advantage of malignant thyroid cells [54].

Radiation exposure causes papillary thyroid cancer as revealed by various studies after the Chernobyl accident [56]. Genome-wide association studies (GWAS) employing Belarusian patients and control subjects demonstrated that the variant rs965513 on 9q22.33 is significantly associated with the radiation-induced papillary thyroid cancer [57]. This variant was identified together with NKX2-1, as those having the strongest rink to papillary and follicular thyroid cancers [42]. Although Foxe1 thyroid conditional null mice are currently not available, they would be a useful model to understand the role of FOXE1 in the pathogenesis of thyroid cancer.

\subsection{PAX8}

2.3.1. PAX8 and Cancer. PAX8 is a crucial transcription factor for organogenesis of the thyroid, kidney, and Müllerian system $[8,58]$. PAX8 is expressed in normal as well as neoplastic renal tissues, and in Wilms' tumors $[58,59]$. PAX8 is a useful marker for Müllerian carcinomas [60] and ovarian cancer $[61,62]$ and can be used to distinguish ovarian serous tumors from malignant mesothelioma [61-64] or from other metastatic tumors such as breast and colon $[63,64]$.

PAX8 is expressed in various thyroid cancers; however, the pattern of expression is somewhat controversial; 


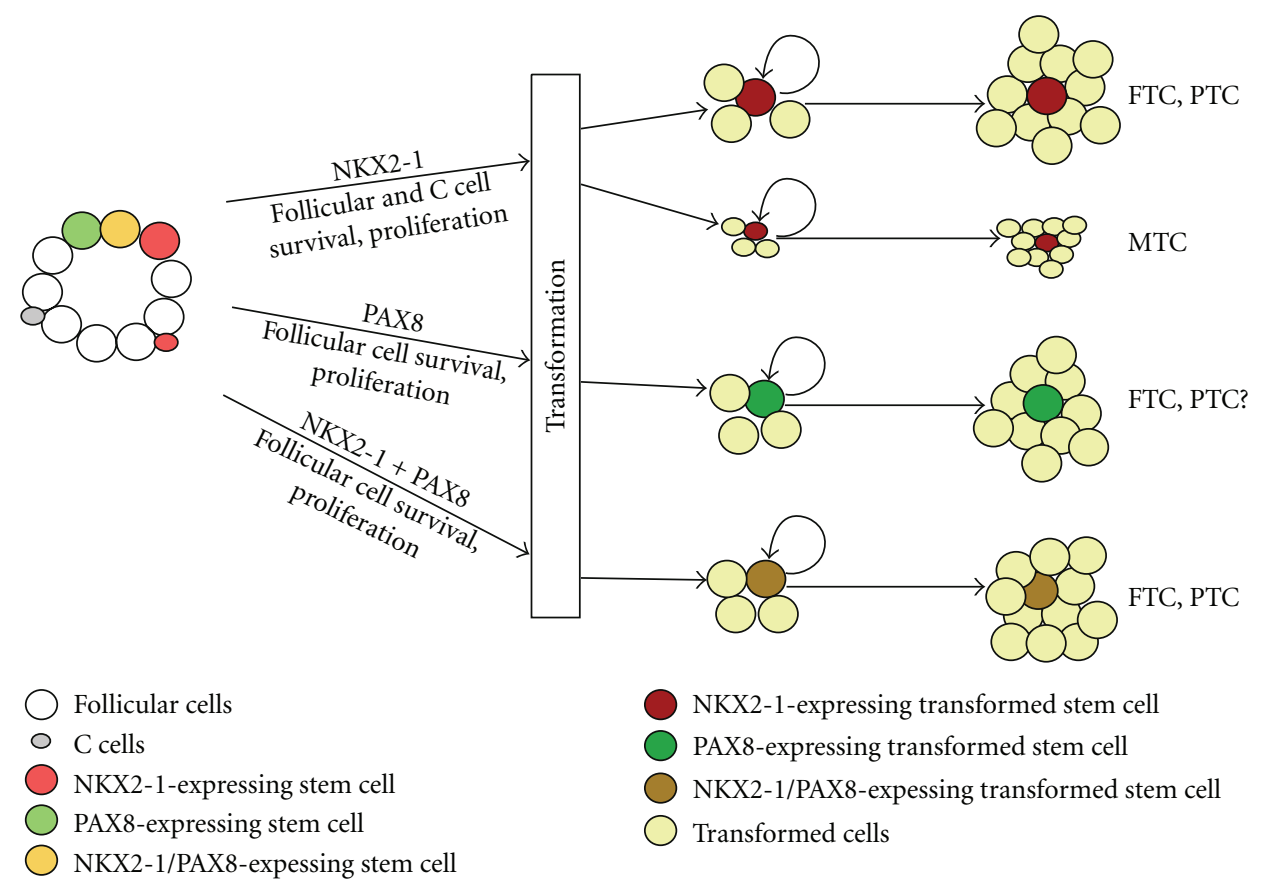

FIGURE 1: Possible involvement of NKX2-1 and/or PAX8 in the maintenance and/or activity of stem cells of the thyroid. Transformation of NKX2-1 and/or PAX8-expressing stem cells leads to thyroid cancer. Transformed NKX2-1 and/or PAX8-expressing stem cells self-renew and proliferate to produce cancer. Upon becoming tumorigenic, most of transformed cells may lose NKX2-1 and/or PAX8 expression. FTC: follicular thyroid carcinoma, PTC: papillary thyroid carcinoma, and MTC: medullary thyroid carcinoma.

one study showed that the nuclear PAX8 staining is correlated with the thyroid differentiation phenotype as seen with NKX2-1 and FOXE1 [27], while others demonstrated that PAX8 is a useful marker for the diagnosis of anaplastic carcinomas [38]. More studies are required to determine the expression pattern and the role of PAX8 in thyroid cancers, including the use of Pax8 thyroid-conditional null mice.

2.3.2. PAX8/PPAR Fusion Oncogene in Thyroid Cancer. The chromosomal translocation of the 2q13-qter region to $3 \mathrm{p} 25$ results in an in-frame fusion protein (PPFP) between most of the coding sequence of PAX8 and the entire translated reading-frame of the nuclear receptor-family member peroxisome proliferator-activated receptor gamma (PPAR $\gamma)$ ([65] reviewed in $[66,67])$. The PPFP has several different PAX8 breakpoints while the PPAR $\gamma$ breakpoint seems to be constant $[65,67,68]$. This fusion protein is more prevalently expressed in follicular thyroid carcinomas (36\%, reviewed in [69]); however, follicular adenomas (11\%), follicular variant of papillary carcinoma (16\%), and Hürthle cell carcinoma (2\%) also express PPFP [68-70]. PPFP has been proposed to be an early follicular thyroid carcinoma-specific oncogene $[65,71]$. Several in vitro studies demonstrated that PPFP has oncogenic activity such as increased cell cycle transition, reduced apoptosis, and enhanced growth [71], which is partly due to PPFP's dominant negative activity to suppress wild-type transcriptional activities of PPAR $\gamma$ $[65,71,72]$, the suggested tumor suppressor $[73,74]$. PPFP can also work as a dominant negative inhibitor of wild-type
PPAR $y$ in vivo [75]. Further studies are required to establish the mechanisms for the PPFP-mediated tumorigenesis.

\section{Thyroid-Specific Transcription Factors, Cancer, and Stem Cells}

Normal embryogenesis is believed to share many of the same pathways as neoplasia, such as Wnt/ $\beta$-catenin, Hedgehog, and Notch pathways. These signaling pathways are also involved in the maintenance and/or activity of stem cells, while their dysregulation plays a role in tumorigenesis (reviewed in [76-80]). It is increasingly recognized that homeobox proteins including PAX proteins play a critical role in stem cell maintenance $[4,81]$. PAX3 or PAX7 is essential for generating the cell pool of muscle progenitors from which satellite cells derive [82]. Overexpression of PAX3 and 7 is frequently found in pediatric soft-tissue malignant tumor rhabdomyosarcomas [83, 84]. PAX6 is essential for maintenance of the multipotency of retinal progenitor cells [85]. On the other hand, HOX genes are expressed in hematopoietic cells in a stage- and lineage-specific manner, and are implicated in leukemogenesis [81]; for instance, HOXA10 is a critical regulator for haematopoietic stem cells, and erythroid and megakaryocyte development [86], while HOXA9 is required for normal hematopoietic stem cell function [87]. The involvements of other homeobox genes in the maintenance of stem cells are described in various tissues including brain [88] and kidney [89]. In the prostate, NKX31 , another member of the NKX gene family, is required for stem cell maintenance [90]. The targeted deletion of Pten, 
a tumor suppressor gene in castration-resistant NKX3-1expressing cells, results in rapid carcinoma formation after androgen-mediated regeneration [90].

The three transcription factors, NKX2-1, FOXE1, and PAX8, are critical for normal embryogenesis and appear to play a role in tumorigenesis in various tissues where they are expressed, including the thyroid. By analogy to other homeodomain/PAX proteins, it is likely that NKX2-1 and PAX8 may be involved in the maintenance and/or activity of stem cells in the thyroid, dysregulation of which may lead to thyroid cancer (Figure 1). Currently, it is not clear whether FOX transcription factors are involved in stem cell maintenance/activity [3]. Knockout mouse studies demonstrated that in the absence of NKX2-1, primordium cells to both thyroid follicular and $\mathrm{C}$ cells disintegrate during thyroid organogenesis $[16,91]$, while PAX8 is required for the survival of follicular cells [17]. It would be interesting to determine whether NKX2-1 and/or PAX8-expressing stem/ progenitor cells exist that can rapidly form cancers upon targeted disruption of a tumor suppressor gene in cell pools, similar to that seen with NKX3-1. In this regard, NKX2-1 in lung cancers may be more analogous to this scenario since NKX2-1 is a lineage-specific oncogene and is required for survival of a subset of adenocarcinoma cells [33-35].

\section{Conclusions}

It appears that most transcription factors, if not all, that are critical for developmental process are involved in the maintenance and/or activity of stem cells, whose dysregulation results in cancers. Currently, it is entirely unknown whether and/or how the thyroid-specific transcription factors NKX21, FOXE1, and PAX8 are related to stem/progenitor cells of the thyroid that may lead to cancer when dysregulated. Identification/characterization of thyroid stem/progenitor cells, their relation to the expression of NKX2-1, FOXE1, and/or PAX8, and more detailed characterization of various thyroid cancers and/or cancer cells, particularly in relation to the expression of these transcription factors, are urgently required in order to better understand the roles of NKX2-1, FOXE1, and PAX8 in thyroid cancer.

\section{References}

[1] C. Cillo, A. Faiella, M. Cantile, and E. Boncinelli, "Homeobox genes and cancer," Experimental Cell Research, vol. 248, no. 1, pp. 1-9, 1999.

[2] F. D. Nunes, F. C. de Almeida, R. Tucci, and S. C. de Sousa, "Homeobox genes: a molecular link between development and cancer," Pesquisa Odontologica Brasileira, vol. 17, no. 1, pp. 9498, 2003.

[3] S. S. Myatt and E. W. F. Lam, "The emerging roles of forkhead box (Fox) proteins in cancer," Nature Reviews Cancer, vol. 7, no. 11, pp. 847-859, 2007.

[4] D. Lang, S. K. Powell, R. S. Plummer, K. P. Young, and B. A. Ruggeri, "PAX genes: roles in development, pathophysiology, and cancer," Biochemical Pharmacology, vol. 73, no. 1, pp. 114, 2007.
[5] S. Guazzi, M. Price, M. De Felice, G. Damante, M. G. Mattei, and R. Di Lauro, "Thyroid nuclear factor 1 (TTF-1) contains a homeodomain and displays a novel DNA binding specificity," EMBO Journal, vol. 9, no. 11, pp. 3631-3639, 1990.

[6] K. Mizuno, F. J. Gonzalez, and S. Kimura, "Thyroid-specific enhancer-binding protein (T/EBP): cDNA cloning, functional characterization, and structural identity with thyroid transcription factor TTF-1," Molecular and Cellular Biology, vol. 11, no. 10, pp. 4927-4933, 1991.

[7] M. Zannini, V. Avantaggiato, E. Biffali et al., "TTF-2, a new forkhead protein, shows a temporal expression in the developing thyroid which is consistent with a role in controlling the onset of differentiation," EMBO Journal, vol. 16, no. 11, pp. 3185-3197, 1997.

[8] D. Plachov, K. Chowdhurry, C. Walther, D. Simon, J. L. Guenet, and P. Gruss, "Pax8, a murine paired box gene expressed in the developing excretory system and thyroid gland," Development, vol. 110, no. 2, pp. 643-651, 1990.

[9] F. Kikkawa, F. J. Gonzalez, and S. Kimura, "Characterization of a thyroid-specific enhancer located 5.5 kilobase pairs upstream of the human thyroid peroxidase gene," Molecular and Cellular Biology, vol. 10, no. 12, pp. 6216-6224, 1990.

[10] H. Francis-Lang, M. Zannini, M. De Felice, M. T. Berlingieri, A. Fusco, and R. Di Lauro, "Multiple mechanisms of interference between transformation and differentiation in thyroid cells," Molecular and Cellular Biology, vol. 12, no. 12, pp. 57935800, 1992.

[11] M. Zannini, H. Francis-Lang, D. Plachov, and R. Di Lauro, "Pax-8, a paired domain-containing protein, binds to a sequence overlapping the recognition site of a homeodomain and activates transcription from two thyroid-specific promoters," Molecular and Cellular Biology, vol. 12, no. 9, pp. 42304241, 1992.

[12] M. Ohno, M. Zannini, O. Levy, N. Carrasco, and R. Di Lauro, "The paired-domain transcription factor Pax8 binds to the upstream enhancer of the rat sodium/iodide symporter gene and participates in both thyroid-specific and cyclic-AMPdependent transcription," Molecular and Cellular Biology, vol. 19, no. 3, pp. 2051-2060, 1999.

[13] P. Santisteban, A. Acebron, M. Polycarpou-Schwarz, and R. Di Lauro, "Insulin and insulin-like growth factor I regulate a thyroid-specific nuclear protein that binds to the thyroglobulin promoter," Molecular Endocrinology, vol. 6, no. 8, pp. 13101317, 1992.

[14] G. Damante and R. Di Lauro, "Thyroid-specific gene expression," Biochimica et Biophysica Acta, vol. 1218, no. 3, pp. 255266, 1994.

[15] M. De Felice, C. Ovitt, E. Biffali et al., "A mouse model for hereditary thyroid dysgenesis and cleft palate," Nature Genetics, vol. 19, no. 4, pp. 395-398, 1998.

[16] S. Kimura, Y. Hara, T. Pineau et al., "The T/ebp null mouse: thyroid-specific enhancer-binding protein is essential for the organogenesis of the thyroid, lung, ventral forebrain, and pituitary," Genes and Development, vol. 10, no. 1, pp. 60-69, 1996.

[17] A. Mansouri, K. Chowdhury, and P. Gruss, "Follicular cells of the thyroid gland require Pax8 gene function," Nature Genetics, vol. 19, no. 1, pp. 87-90, 1998.

[18] M. Felice and R. Lauro, "Murine models for the study of thyroid gland development," Endocrine Development, vol. 10, pp. 1-14, 2007.

[19] N. Dathan, R. Parlato, A. Rosica, M. De Felice, and R. Di Lauro, "Distribution of the titf2/foxel gene product is consistent with an important role in the development of foregut endoderm, 
palate, and hair," Developmental Dynamics, vol. 224, no. 4, pp. 450-456, 2002.

[20] J. Pohlenz, A. Dumitrescu, D. Zundel et al., "Partial deficiency of thyroid transcription factor 1 produces predominantly neurological defects in humans and mice," Journal of Clinical Investigation, vol. 109, no. 4, pp. 469-473, 2002.

[21] H. Krude, B. Schütz, H. Biebermann et al., "Choreoathetosis, hypothyroidism, and pulmonary alterations due to human NKX2-1 haploinsufficiency," Journal of Clinical Investigation, vol. 109, no. 4, pp. 475-480, 2002.

[22] M. A. A. P. Willemsen, G. J. Breedveld, S. Wouda et al., "Brain-Thyroid-Lung syndrome: a patient with a severe multisystem disorder due to a de novo mutation in the thyroid transcription factor 1 gene," European Journal of Pediatrics, vol. 164, no. 1, pp. 28-30, 2005.

[23] R. J. Clifton-Bligh, J. M. Wentworth, P. Heinz et al., "Mutation of the gene encoding human TTF-2 associated with thyroid agenesis, cleft palate and choanal atresia," Nature Genetics, vol. 19, no. 4, pp. 399-401, 1998.

[24] M. Castanet, S. M. Park, A. Smith et al., "A novel loss-offunction mutation in TTF-2 is associated with congenital hypothyroidism, thyroid agenesis and cleft palate," Human Molecular Genetics, vol. 11, no. 17, pp. 2051-2059, 2002.

[25] C. Di Loreto, V. Di Lauro, F. Puglisi, G. Damante, D. Fabbro, and C. A. Beltrami, "Immunocytochemical expression of tissue specific transcription factor-1 in lung carcinoma," Journal of Clinical Pathology, vol. 50, no. 1, pp. 30-32, 1997.

[26] D. Tan, Q. Li, G. Deeb et al., "Thyroid transcription factor1 expression prevalence and its clinical implications in nonsmall cell lung cancer: a high-throughput tissue microarray and immunohistochemistry study," Human Pathology, vol. 34, no. 6, pp. 597-604, 2003.

[27] P. Zhang, H. Zuo, Y. Nakamura, M. Nakamura, T. Wakasa, and K. Kakudo, "Immunohistochemical analysis of thyroidspecific transcription factors in thyroid tumors," Pathology International, vol. 56, no. 5, pp. 240-245, 2006.

[28] M. Bongiovanni, P. M. Sadow, and W. C. Faquin, "Poorly differentiated thyroid carcinoma: a cytologic-histologic review," Advances in Anatomic Pathology, vol. 16, no. 5, pp. 283-289, 2009.

[29] N. Nakamura, E. Miyagi, S. I. Murata, A. Kawaoi, and R. Katoh, "Expression of thyroid transcription factor-1 in normal and neoplastic lung tissues," Modern Pathology, vol. 15, no. 10, pp. 1058-1067, 2002.

[30] J. Moldvay, M. Jackel, K. Bogos et al., "The role of TTF-1 in differentiating primary and metastatic lung adenocarcinomas," Pathology and Oncology Research, vol. 10, no. 2, pp. 85-88, 2004.

[31] N. H. Myong, "Thyroid transcription factor-1 (TTF-1) expression in human lung carcinomas: its prognostic implication and relationship with wxpressions of p53 and Ki-67 proteins," Journal of Korean Medical Science, vol. 18, no. 4, pp. 494-500, 2003.

[32] J. A. Barletta, S. Perner, A. J. Iafrate et al., "Clinical significance of TTF-1 protein expression and TTF-1 gene amplification in lung adenocarcinoma," Journal of Cellular and Molecular Medicine, vol. 13, no. 8B, pp. 1977-1986, 2009.

[33] K. A. Kwei, Y. H. Kim, L. Girard et al., "Genomic profiling identifies TITF1 as a lineage-specific oncogene amplified in lung cancer," Oncogene, vol. 27, no. 25, pp. 3635-3640, 2008.

[34] H. Tanaka, K. Yanagisawa, K. Shinjo et al., "Lineage-specific dependency of lung adenocarcinomas on the lung development regulator TTF-1," Cancer Research, vol. 67, no. 13, pp. 6007-6011, 2007.
[35] B. A. Weir, M. S. Woo, G. Getz et al., "Characterizing the cancer genome in lung adenocarcinoma," Nature, vol. 450, no. 7171, pp. 893-898, 2007.

[36] D. Fabbro, C. Di Loreto, C. A. Beltrami, A. Belfiore, R. Di Lauro, and G. Damante, "Expression of thyroid-specific transcription factors TTF-1 and PAX-8 in human thyroid neoplasms," Cancer Research, vol. 54, no. 17, pp. 4744-4749, 1994.

[37] N. G. Ordóñez, "Thyroid transcription factor-1 is a marker of lung and thyroid carcinomas," Advances in anatomic pathology, vol. 7, no. 2, pp. 123-127, 2000.

[38] D. Nonaka, Y. Tang, L. Chiriboga, M. Rivera, and R. Ghossein, "Diagnostic utility of thyroid transcription factors Pax8 and TTF-2 (FoxE1) in thyroid epithelial neoplasms," Modern Pathology, vol. 21, no. 2, pp. 192-200, 2008.

[39] R. Katoh, E. Miyagi, N. Nakamura et al., "Expression of thyroid transcription factor-1 (TTF-1) in human C cells and medullary thyroid carcinomas," Human Pathology, vol. 31, no. 3, pp. 386-393, 2000.

[40] T. Kondo, T. Nakazawa, D. Ma et al., "Epigenetic silencing of TTF-1/NKX2-1 through DNA hypermethylation and histone H3 modulation in thyroid carcinomas," Laboratory Investigation, vol. 89, no. 7, pp. 791-799, 2009.

[41] W. C. G. Van Staveren, D. W. Solís, L. Delys et al., "Human thyroid tumor cell lines derived from different tumor types present a common dedifferentiated phenotype," Cancer Research, vol. 67, no. 17, pp. 8113-8120, 2007.

[42] J. Gudmundsson, P. Sulem, D. F. Gudbjartsson et al., "Common variants on $9 \mathrm{q} 22.33$ and $14 \mathrm{q} 13.3$ predispose to thyroid cancer in European populations," Nature Genetics, vol. 41, no. 4, pp. 460-464, 2009.

[43] E. S. W. Ngan, B. H. H. Lang, T. Liu et al., "A germline mutation $(\mathrm{A} 339 \mathrm{~V})$ in thyroid transcription factor-1 (TITF1/NKX2.1) in patients with multinodular goiter and papillary thyroid carcinoma," Journal of the National Cancer Institute, vol. 101, no. 3, pp. 162-175, 2009.

[44] T. Kusakabe, A. Kawaguchi, R. Kawaguchi, L. Feigenbaum, and S. Kimura, "Thyrocyte-specific expression of Cre recombinase in transgenic mice," Genesis, vol. 39, no. 3, pp. 212-216, 2004.

[45] T. Kusakabe, A. Kawaguchi, N. Hoshi, R. Kawaguchi, S. Hoshi, and S. Kimura, "Thyroid-specific enhancer-binding protein/NKX2.1 is required for the maintenance of ordered architecture and function of the differentiated thyroid," Molecular Endocrinology, vol. 20, no. 8, pp. 1796-1809, 2006.

[46] S. Hoshi, N. Hoshi, M. Okamoto et al., "Role of NKX2-1 in N bis(2-hydroxypropyl)-nitrosamine-induced thyroid adenoma in mice," Carcinogenesis, vol. 30, no. 9, pp. 1614-1619, 2009.

[47] P. E. Macchia, M. G. Mattei, P. Lapi, G. Fenzi, and R. Di Lauro, "Cloning, chromosomal localization and identification of polymorphisms in the human thyroid transcription factor 2 gene (TITF2)," Biochimie, vol. 81, no. 5, pp. 433-440, 1999.

[48] E. Holmberg, B. L. Rozell, and R. Toftgard, "Differential allele loss on chromosome 9q22.3 in human non-melanoma skin cancer," British Journal of Cancer, vol. 74, no. 2, pp. 246-250, 1996.

[49] I. Venza, M. Visalli, B. Tripodo et al., "FOXE1 is a target for aberrant methylation in cutaneous squamous cell carcinoma," British Journal of Dermatology, vol. 162, no. 5, pp. 1093-1097, 2010.

[50] K. Brune, S. M. Hong, A. Li et al., "Genetic and epigenetic alterations of familial pancreatic cancers," Cancer Epidemiology Biomarkers and Prevention, vol. 17, no. 12, pp. 3536-3542, 2008. 
[51] D. J. Weisenberger, B. N. Trinh, M. Campan et al., "DNA methylation analysis by digital bisulfite genomic sequencing and digital MethyLight," Nucleic Acids Research, vol. 36, no. 14, pp. 4689-4698, 2008.

[52] I. Venza, M. Visalli, B. Tripodo, M. Lentini, D. Teti, and M. Venza, "Investigation into FOXE1 genetic variations in cutaneous squamous cell carcinoma," British Journal of Dermatology, vol. 162, no. 3, pp. 681-683, 2010.

[53] M. J. Sequeira, J. M. Morgan, D. Fuhrer, M. H. Wheeler, B. Jasani, and M. Ludgate, "Thyroid transcription factor-2 gene expression in benign and malignant thyroid lesions," Thyroid, vol. 11, no. 11, pp. 995-1001, 2001.

[54] I. Landa, S. Ruiz-Llorente, C. Montero-Conde et al., "The variant rs1867277 in FOXE1 gene confers thyroid cancer susceptibility through the recruitment of USF1/USF2 transcription factors," PLoS Genetics, vol. 5, no. 9, Article ID e1000637, 2009.

[55] R. Parlato, A. Rosica, A. Rodriguez-Mallon et al., "An integrated regulatory network controlling survival and migration in thyroid organogenesis," Developmental Biology, vol. 276, no. 2, pp. 464-475, 2004.

[56] D. Williams, "Cancer after nuclear fallout: lessons from the Chernobyl accident," Nature Reviews Cancer, vol. 2, no. 7, pp. 543-549, 2002.

[57] M. Takahashi, V. A. Saenko, T. I. Rogounovitch et al., "The FOXE1 locus is a major genetic determinant for radiationrelated thyroid carcinoma in Chernobyl," Human Molecular Genetics, vol. 19, no. 12, pp. 2516-2523, 2010.

[58] A. Poleev, H. Fickenscher, S. Mundlos et al., "PAX8, a human paired box gene: Isolation and expression in developing thyroid, kidney and Wilms' tumors," Development, vol. 116, no. 3, pp. 611-623, 1992.

[59] G. X. Tong, W. M. Yu, N. T. Beaubier et al., "Expression of PAX8 in normal and neoplastic renal tissues: an immunohistochemical study," Modern Pathology, vol. 22, no. 9, pp. 12181227, 2009.

[60] W. Wiseman, C. W. Michael, and M. H. Roh, "Diagnostic utility of PAX 8 and PAX2 immunohistochemistry in the identification of metastatic Mullerian carcinoma in effusions," Diagnostic Cytopathology. In press.

[61] A. R. Laury, J. L. Hornick, R. Perets et al., "PAX8 reliably distinguishes ovarian serous tumors from malignant mesothelioma," American Journal of Surgical Pathology, vol. 34, no. 5, pp. 627-635, 2010.

[62] D. Nonaka, L. Chiriboga, and R. A. Soslow, "Expression of Pax8 as a useful marker in distinguishing ovarian carcinomas from mammary carcinomas," American Journal of Surgical Pathology, vol. 32, no. 10, pp. 1566-1571, 2008.

[63] N. J. Bowen, S. Logani, E. B. Dickerson et al., "Emerging roles for PAX8 in ovarian cancer and endosalpingeal development," Gynecologic Oncology, vol. 104, no. 2, pp. 331-337, 2007.

[64] M. Fujiwara, J. Taube, M. Sharma, T. H. McCalmont, and J. Kim, "PAX8 discriminates ovarian metastases from adnexal tumors and other cutaneous metastases," Journal of Cutaneous Pathology, vol. 37, no. 9, pp. 938-943, 2010.

[65] T. G. Kroll, P. Sarraf, L. Pecciarini et al., "PAX8-PPAR $\gamma 1$ fusion in oncogene human thyroid carcinoma," Science, vol. 289, no. 5483, pp. 1357-1360, 2000.

[66] M. Sobrinho-Simões, V. Máximo, A. S. Rocha et al., "Intragenic mutations in thyroid cancer," Endocrinology and Metabolism Clinics of North America, vol. 37, no. 2, pp. 333362, 2008.
[67] N. L. Eberhardt, S. K. G. Grebe, B. McIver, and H. V. Reddi, "The role of the PAX8/PPAR $\gamma$ fusion oncogene in the pathogenesis of follicular thyroid cancer," Molecular and Cellular Endocrinology, vol. 321, no. 1, pp. 50-56, 2010.

[68] A. R. Marques, C. Espadinha, A. L. Catarino et al., "Expression of PAX8-PPAR $\gamma 1$ rearrangements in both follicular thyroid carcinomas and adenomas," Journal of Clinical Endocrinology and Metabolism, vol. 87, no. 8, pp. 3947-3952, 2002.

[69] K. A. Placzkowski, H. V. Reddi, S. K. G. Grebe, N. L. Eberhardt, and B. McIver, "The role of the PAX8/PPAR $y$ fusion oncogene in thyroid cancer," PPAR Research, vol. 2008, Article ID 672829, 10 pages, 2008.

[70] L. Cheung, M. Messina, A. Gill et al., "Detection of the PAX8-PPAR $y$ fusion oncogene in both follicular thyroid carcinomas and adenomas," Journal of Clinical Endocrinology and Metabolism, vol. 88, no. 1, pp. 354-357, 2003.

[71] J. G. Powell, X. Wang, B. L. Allard et al., "The PAX8/PPAR $\gamma$ fusion oncoprotein transforms immortalized human thyrocytes through a mechanism probably involving wild-type PPAR $y$ inhibition," Oncogene, vol. 23, no. 20, pp. 3634-3641, 2004.

[72] A. Y.M. Au, C. McBride, K. G. Wilhelm Jr. et al., "PAX8peroxisome proliferator-activated receptor $\gamma(\operatorname{PPAR} \gamma)$ disrupts normal PAX8 or PPAR $y$ transcriptional function and stimulates follicular thyroid cell growth," Endocrinology, vol. 147, no. 1, pp. 367-376, 2006.

[73] D. Bonofiglio, E. Cione, H. Qi et al., "Combined low doses of PPAR $\gamma$ and RXR ligands trigger an intrinsic apoptotic pathway in human breast cancer cells," American Journal of Pathology, vol. 175, no. 3, pp. 1270-1280, 2009.

[74] J. Yu, BO. Shen, E. S. H. Chu et al., "Inhibitory role of peroxisome proliferator-activated receptor gamma in hepatocarcinogenesis in mice and in vitro," Hepatology, vol. 51, no. 6, pp. 2008-2019, 2010.

[75] Y. Yin, H. Yuan, X. Zeng, L. Kopelovich, and R. I. Glazer, "Inhibition of peroxisome proliferator-activated receptor $\gamma$ increases estrogen receptor-dependent tumor specification," Cancer Research, vol. 69, no. 2, pp. 687-694, 2009.

[76] M. Mimeault and S. K. Batra, "Frequent deregulations in the hedgehog signaling network and cross-talks with the epidermal growth factor receptor pathway involved in cancer progression and targeted therapies," Pharmacological Reviews, vol. 62, no. 3, pp. 497-524, 2010.

[77] M. W. Saif and E. Chu, "Biology of colorectal cancer," Cancer Journal, vol. 16, no. 3, pp. 196-201, 2010.

[78] L. Yin, O. C. Velazquez, and Z. J. Liu, "Notch signaling: Emerging molecular targets for cancer therapy," Biochemical Pharmacology, vol. 80, no. 5, pp. 690-701, 2010.

[79] P. Wend, J. D. Holland, U. Ziebold, and W. Birchmeier, "Wnt signaling in stem and cancer stem cells," Seminars in Cell and Developmental Biology, vol. 21, no. 8, pp. 855-863, 2010.

[80] P. Heretsch, L. Tzagkaroulaki, and A. Giannis, "Modulators of the hedgehog signaling pathway," Bioorganic and Medicinal Chemistry, vol. 18, no. 18, pp. 6613-6624, 2010.

[81] S. Samuel and H. Naora, "Homeobox gene expression in cancer: Insights from developmental regulation and deregulation," European Journal of Cancer, vol. 41, no. 16, pp. 2428 2437, 2005.

[82] F. Relaix, D. Rocancourt, A. Mansouri, and M. Buckingham, "A Pax3/Pax7-dependent population of skeletal muscle progenitor cells," Nature, vol. 435, no. 7044, pp. 948-953, 2005. 
[83] M. Bernasconi, A. Remppis, W. J. Fredericks, F. J. Rauscher, and B. W. Schäfer, "Induction of apoptosis in rhabdomyosarcoma cells through down-regulation of PAX proteins," Proceedings of the National Academy of Sciences of the United States of America, vol. 93, no. 23, pp. 13164-13169, 1996.

[84] N. Tiffin, R. D. Williams, J. Shipley, and K. Pritchard-Jones, "PAX7 expression in embryonal rhabdomyosarcoma suggests an origin in muscle satellite cells," British Journal of Cancer, vol. 89, no. 2, pp. 327-332, 2003.

[85] T. Marquardt, R. Ashery-Padan, N. Andrejewski, R. Scardigli, F. Guillemot, and P. Gruss, "Pax6 is required for the multipotent state of retinal progenitor cells," Cell, vol. 105, no. 1, pp. 43-55, 2001.

[86] M. Magnusson, A. C. M. Brun, N. Miyake et al., "HOXA10 is a critical regulator for hematopoietic stem cells and erythroid/megakaryocyte development," Blood, vol. 109, no. 9, pp. 3687-3696, 2007.

[87] H. J. Lawrence, J. Christensen, S. Fong et al., "Loss of expression of the Hoxa-9 homeobox gene impairs the proliferation and repopulating ability of hematopoietic stem cells," Blood, vol. 106, no. 12, pp. 3988-3994, 2005.

[88] A. Lavado, O. V. Lagutin, L. M. L. Chow, S. J. Baker, and G. Oliver, "Prox1 Is required for granule cell maturation and intermediate progenitor maintenance during brain neurogenesis," PLoS Biology, vol. 8, no. 8, pp. 43-44, 2010.

[89] M. Self, O. V. Lagutin, B. Bowling et al., "Six2 is required for suppression of nephrogenesis and progenitor renewal in the developing kidney," EMBO Journal, vol. 25, no. 21, pp. 52145228, 2006.

[90] XI. Wang, M. Kruithof-de Julio, K. D. Economides et al., "A luminal epithelial stem cell that is a cell of origin for prostate cancer," Nature, vol. 461, no. 7263, pp. 495-500, 2009.

[91] T. Kusakabe, N. Hoshi, and S. Kimura, "Origin of the ultimobranchial body cysts: T/ebp/Nkx2.1 expression is required for development and fusion of the ultimobranchial body to the thyroid," Developmental Dynamics, vol. 235, no. 5, pp. 13001309, 2006. 


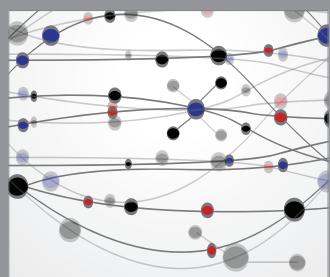

The Scientific World Journal
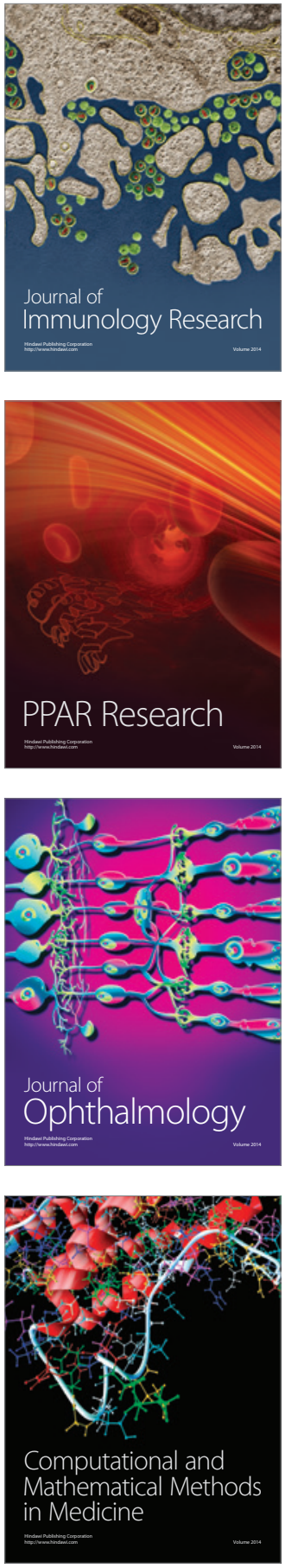

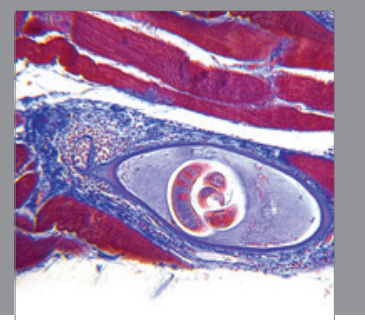

Gastroenterology

Research and Practice
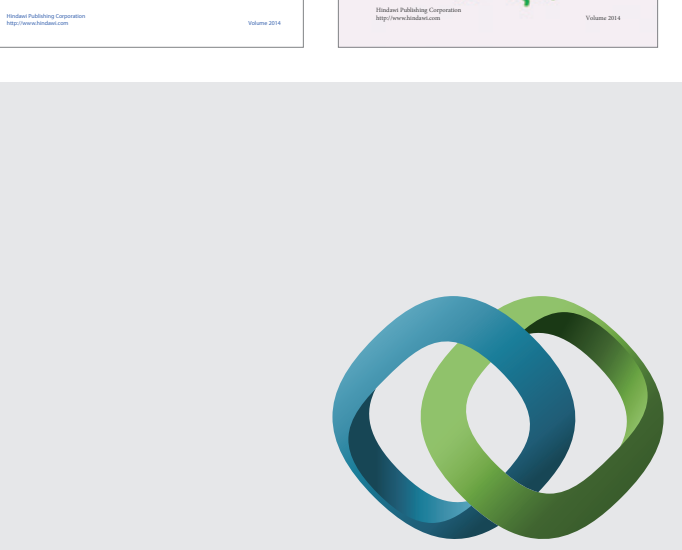

\section{Hindawi}

Submit your manuscripts at

http://www.hindawi.com
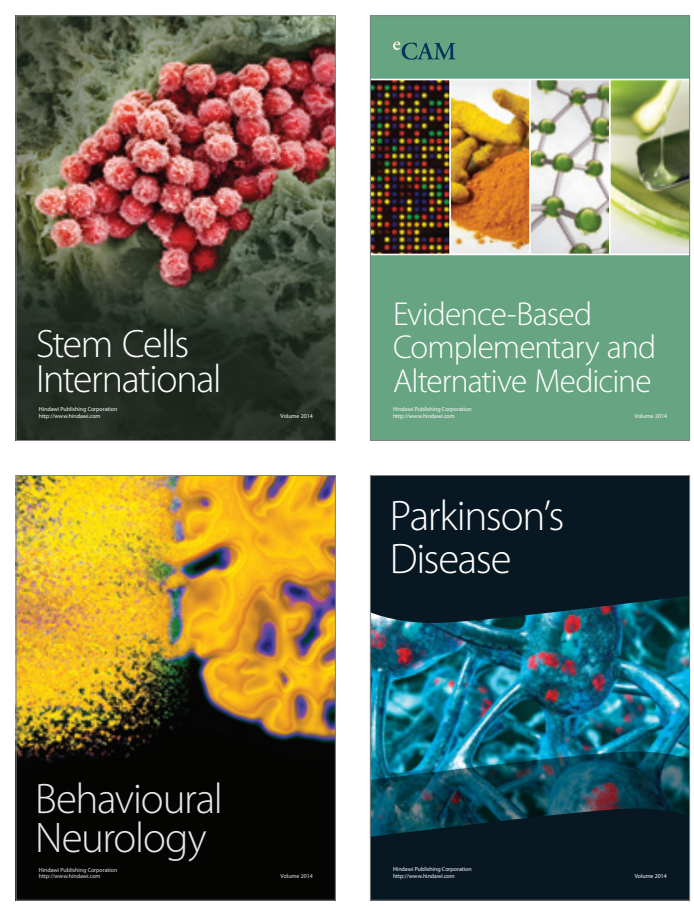

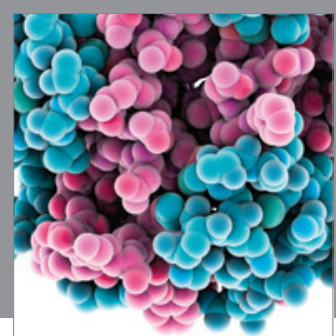

Journal of
Diabetes Research

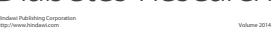

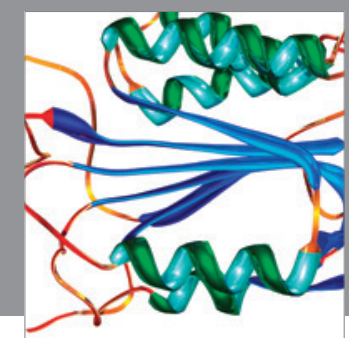

Disease Markers
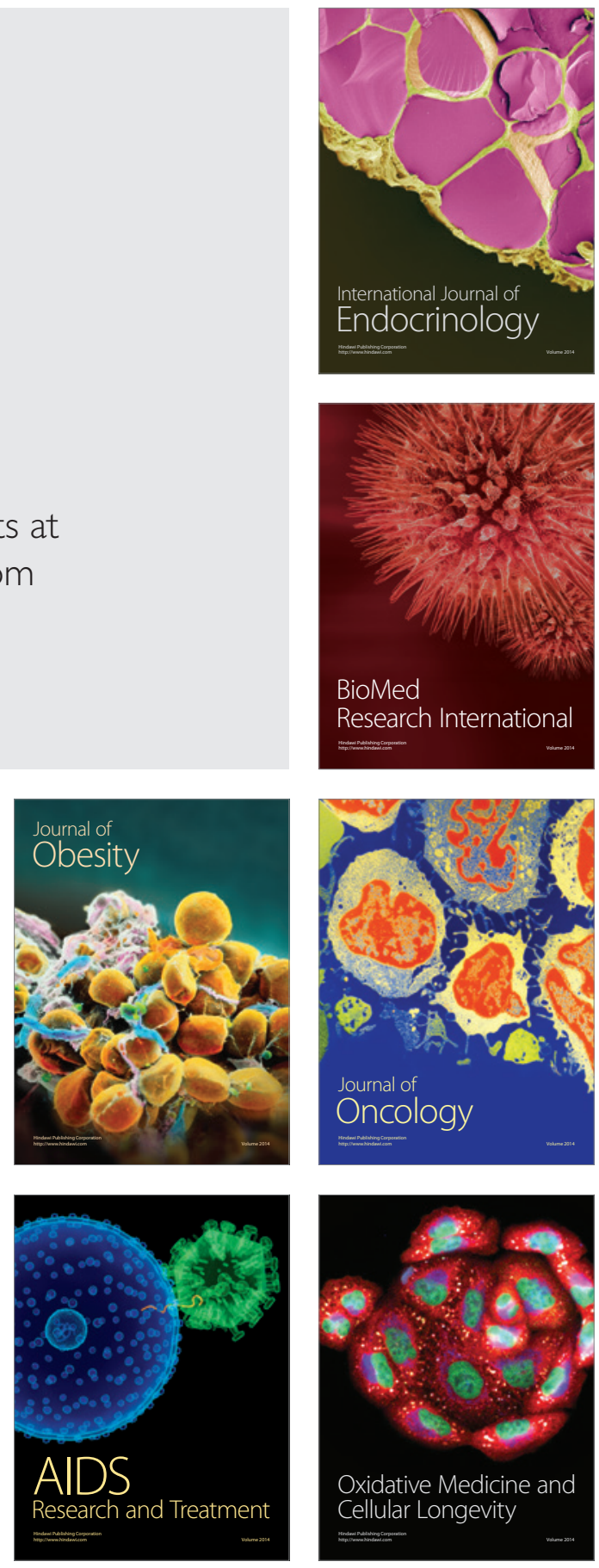